\title{
Outcome of psychiatric intervention in factitious illness by proxy (Munchausen's syndrome by proxy)
}

\author{
Birgit Berg, David P H Jones
}

\begin{abstract}
Objective-To determine the outcome for children after psychiatric intervention in cases of factitious illness by proxy.

Methods-All 17 children from 16 families, selected for admission to the Park Hospital Oxford family unit 1992-96 were followed up after a mean of 27 months. Information was obtained on the children and their carers from general practitioners, social workers or both; 13 of the children and carers were interviewed.

Results-All patients were at the severe end of the abuse spectrum; 12 involving direct induction of illness, 1 tampering with samples to mimic illness, and 4 fabrication of symptoms. The biological mother was the abuser in all cases. Four children and their parents had been initially admitted for assessment, and 13 for treatment to decide whether family reunification was viable. The 4 assessments clarified diagnosis, enabling improved care plans to be made. Of the 13 treatment cases, 10 were reunited with parents after a mean of $71 / 2$ weeks' admission, whereas 3 were discharged to out of home care. There was a further episode of induced illness in 1 of the reunited children. Although some mothers had continuing mental health difficulties, only 1 of the other reunited cases had appreciable parent-child relationship difficulties (not requiring referral to psychiatric services). The children did well in their development, growth, and adjustment.

Conclusion-Family reunification is feasible for certain cases, but long term follow up is necessary to ensure the child's safety and to identify deterioration in parent's mental health. The outcome for reunited children compared well with reported untreated cases.

(Arch Dis Child 1999;81:465-472)
\end{abstract}

Park Hospital for Children, Old Road, Headington, Oxford OX3 7LQ, UK

B Berg

D P H Jones

Correspondence to: Dr Jones

Accepted 4 August 1999

In 1975, Meadow described a serious form of child abuse, terming it Munchausen's syndrome by proxy. ${ }^{1}$ In a recent review, Jones and Bools $^{2}$ preferred the term factitious illness by proxy, as a relatively neutral term encompass- ing the main elements of a complex set of phenomena including:

- The fabrication of an illness in a child (with a range of subtypes and severity)

- The mental state of the fabricator (with putative psychological processes, psychiatric diagnoses, and effects on the parentchild attachment or interaction)

- The effects on the child's development (both physical and emotional).

Most commentators have considered factitious illness by proxy unsuitable for psychological treatment aimed at family reunification. ${ }^{34}$ Case management has focused principally on disentangling diagnostic difficulties, conveying the conclusion of fabrication to parents, and planning child protection. This was because of the severity of the initial abuse, ${ }^{5}$ and apparently severe personality disorder in some of the perpetrating parents, ${ }^{6}$ combined with the poor outcome for children and persisting parenting problems on follow up. ${ }^{7}$ Despite this generally negative prognostic picture, an appreciable minority of affected children either remain with their birth parents, or return home after a variable period, frequently in the absence of planned psychiatric or social work intervention, which might be expected to improve their outcome. ${ }^{8} 9$

The rationale for considering psychological treatment for this form of abuse arises from a composite series of considerations.

- It brings case planning and child safety to the foreground, permitting professional scrutiny of care plans for the child

- If it can be shown to be effective and safe, it should enable parents to care for their children again

- All children have the right to be brought up within their birth family, if it is safe for them to do so

- Psychological treatment focused upon an index case of factitious illness by proxy might improve the quality of life for current and future siblings, who are known to suffer considerable morbidity, ${ }^{9}$ and even mortality, ${ }^{6}{ }^{10}$ in the absence of intervention own problems, even if it is considered the only safe option. 
Jones and Bools ${ }^{2}$ summarised single case reports of psychiatric treatment aimed at family reunification, commenting that successful interventions usually focused on cases where a parent has taken responsibility for the abuse, and has been considered amenable to psychological treatment. Case reports are more likely to be published where successful intervention has occurred, although one repor $t^{11}$ described a less optimistic picture of psychiatric intervention, noting that despite reunification the children developed considerable psychiatric problems. In a series of 41 cases identified within a specialist children's hospital, the authors describe their liaison with locally based services and efforts to encourage continuing therapeutic work to occur in the community. ${ }^{12} 13$ However, psychiatric treatment aimed at family reunification was not part of their remit.

The Park Hospital for Children's family unit has traditionally admitted one or two cases of factitious illness by proxy annually. The numbers have increased during the past seven years. We report here on the outcome for a consecutive series of cases of factitious illness by proxy who received psychiatric intervention. We believe this is the first systematic report of a series with psychiatric intervention. The duration of intervention varied with the aims of the admission. Some admissions comprised in depth assessments, whereas most examined the prospects for family reunification. Assessment and treatment work were undertaken by a multidisciplinary child and family psychiatric team, whose work concentrates on child maltreatment. The treatment work is a mixture of family work, individual treatment for parents using focal psychotherapeutic methods, including cognitive behaviour therapy, and brief focal psychotherapy combined with systemic family therapy. The theoretical orientation of the team is founded on principles of infantparent attachment theory. The team's clinical assessment and process of treatment is described in detail elsewhere. ${ }^{14}{ }^{15}$ We now report the outcome for all children and families who were admitted to our inpatient unit between 1992 and 1996.

\section{Methods}

PROJECT DESIGN

We traced the 16 families who had been admitted to the family unit between 1992 and 1996 after a diagnosis of factitious illness by proxy. The families contained 17 children, who were aged between $2 \frac{1}{2}$ and 12 years at the time of follow up. Our aim was to assess index children's subsequent development, their psychological condition and social context, and whether they had suffered further abuse. We also sought to evaluate the psychological state and parenting capacity of the main carer (biological parent or foster/adoptive parent).

\section{SAMPLE DETAILS}

The cases were a mixed group-most were admitted for assessment with a view to exploring whether family reunification was feasible and safe. However, four children, from three families, had briefer, assessment orientated admissions. Of these, one assessment resulted in the conclusion that the previous diagnosis of Munchausen's syndrome by proxy was probably not warranted and that the case represented extreme exaggeration by the mother rather than fabrication. ${ }^{16}$ Therefore, the child and family were discharged home to a community based continuing programme of assistance. In another family, factitious illness by proxy was confirmed, but the case was considered too dangerous, with no prospect that psychiatric treatment would be effective. Hence, this case was discharged to alternative care. The third family with two children was essentially a diagnostic evaluation to confirm (or otherwise) factitious epilepsy by proxy combined with emotional abuse. Ambulatory electroencephalography monitoring was used and the diagnosis confirmed, and a plan for management in the community ensued.

This left 13 children where psychiatric work continued as an inpatient with the aim of establishing sufficient psychological improvement to justify the family's continuing reunification on discharge from the unit.

These 13 "treatment" cases met criteria for Munchausen's syndrome by proxy as described by Rosenberg ${ }^{4}$ and Meadow. ${ }^{16}$ They included one where a previous child had been removed and adopted because of poisoning; the admission to the Park Hospital was for potential reunification with a younger sibling (case 5). The 13 treatment cases included nonaccidental poisoning, injury to the point of facial disfigurement (dermatitis artefacta by proxy), factitious epilepsy, and induced failure to thrive. There were no cases of induced suffocation in our series, although the unit has had subsequent experience of this type of factitious illness by proxy. Therefore, many of the cases were at the severe end of the spectrum of factitious illness by proxy abuse. The biological mother was the abuser in all cases.

Those admitted to the family unit were selected on the basis of the likelihood of successful intervention. Many more were seen in the outpatient clinic, but were considered unsuitable for psychiatric treatment, usually because of persistent parental denial or the severity of the perpetrator's personality disorder. Potential referrers were aware of the unit's policy of only accepting those cases where some degree of acknowledgement of abuse had occurred, thus further skewing the sample. In general, admission was offered to those where the perpetrator showed a degree of acknowledgement of the nature of the problem, and where the team considered psychological treatment was possible. The presence of personality strengths was considered an optimistic prognostic sign. We sought involvement of other family members or friends to assist in the treatment process.

Treatment comprised psychological interventions targeted at: the parent-child relationship, the quality of the child's attachment to each parent, the abuser's own childhood experiences, and the current social network and family dynamics, together with work with the parental couple. ${ }^{15}$ In addition, intensive liaison 
work was undertaken with key professionals from the family's local area. During admission, the level of nursing supervision ranges from 24 hour constant supervision, to the family living relatively independently within a self contained flatlet, with varying levels of intermediary supervision. This enables parents to take increasingly independent care of their children in response to psychological improvement and our clinical estimate of reduced risk and harm to the child. ${ }^{15}$ After discharge, most families remained in contact with our service and this follow up study was part of the continuing clinical care.

\section{ASSESSMENT MEASURES}

The child

Child development was assessed by measuring height, weight, and head circumference and through the "schedule of growing skills" ${ }^{17}$ This assesses the child's capacities in the areas of motor functioning, vision, hearing, speech and language, social skills, and self care. It is particularly valuable for those under 5 years of age, who comprised most of our sample. It has acceptable validity and reliability. ${ }^{17}$

Children over 5 years were assessed with the "child somatisation inventory"18 to see whether they had incorporated their mother's beliefs concerning ill health. This consists of a self administered questionnaire in which the child answers questions concerning his/her perception of health. Garber and Walker ${ }^{19}$ showed that although the item total correlations were in the low to moderate range, the instrument is valid enough to serve as an index of somatisation symptoms.

The child's psychological condition was rated through the "behaviour check list", a self administered 21 item questionnaire completed by the child's main carer, which assesses 14 areas of behaviour. ${ }^{20}$ Reliability and validity have been established, including successfully discriminating between a clinical and a nonclinical group. The cut off point chosen for this sample was 10 .

The child's social context was assessed through a semistructured interview with the main carer, which we developed. It enquired about living arrangements, household composition, life events, and the involvement of other agencies. It also explored the question of re-abuse, and legal orders for child protection. Given the deceptive nature of factitious illness by proxy, we complemented this information on the child with parallel information from the child's social worker, general practitioner, and health visitor (questionnaires are available from the corresponding author).

The child's carer

A brief mental state examination, and face to face interview were undertaken (BB). This covered social situation, household composition, common life events, the carer's insight into events that had led to admission, and attitudes towards both their own health and their child's. In addition, the carer completed the following self administered questionnaires while the interviewer assessed the child's development.

The "parenting stress index" is a self administered, standardised questionnaire consisting of a 100 statements, which produces a total score for the level of stress the main carer was experiencing at the time of our study. Test/retest reliability for this instrument is high over a six month period. Concurrent and predictive validity has been demonstrated. ${ }^{21}$ The areas covered include the child's distractibility, behaviour management, mood, adaptability, acceptability, and demandingness. The parents' section includes statements about attachment, parenting role, depression, sense of competence, relationship with partner, social contacts, and health. The parent is asked to rate their agreement with each statement on a five point scale. The normal range for total score was between 180-250, with a recommended cut off of 260 .

The 30 item "general health questionnaire" has been widely used to detect symptoms of depression and anxiety. ${ }^{22}$ Reliability and validity are high, with a split half reliability of 0.95 . The cut off point for "caseness" used was 8 .

The shortened form of the "social adjustment scale" ${ }^{23}$ is self administered and presents 45 statements on areas including work outside home, household tasks, social and leisure activities, extended family relationships, marital relationships, relationships with children, and the family unit.

\section{PROCEDURES}

We obtained follow up information on the 17 children from the key professional involved (social worker, health visitor, general practitioner, or other clinician). At the same time we discussed any concerns about contacting the families. Where we obtained approval we wrote to the families about our study, asking them to participate. Therefore, all information gathered from the families was complemented by that from another professional highly involved with the family, such as social worker, general practitioner, or health visitor. When we could not see the family, because of the concerns of the key professional or the family declining to take part, we obtained information about the child and family's adjustment from professional sources. Hence, we obtained basic follow up information on all 16 families ( 17 children) with additional interview based follow up information on 12 of these (13 children).

\section{Results}

Sixteen families had been admitted for assessment and/or treatment between 1992 and 1996. Of these, 12 participated, containing 13 children. We did not approach four families; two because the key professional advised against the study (maternal mental health was not stable enough), one adoptive family did not wish to be approached by mental health professionals, and one family did not respond to our letters. This last family had been reviewed comprehensively at the Park Hospital (DJ) immediately before our study, so is included in our report. 
Table 1 Outcome for 17 children admitted for psychiatric assessment and/or treatment

\begin{tabular}{|c|c|c|c|c|c|c|c|c|}
\hline Case/sex & $\begin{array}{l}\text { Type of } \\
\text { abuse }\end{array}$ & $\begin{array}{l}\text { Age when } \\
\text { abused }\end{array}$ & $\begin{array}{l}\text { Family } \\
\text { structure } \\
\text { when abused }\end{array}$ & $\begin{array}{l}\text { Age at } \\
\text { inpatient } \\
\text { admission }\end{array}$ & $\begin{array}{l}\text { Age at } \\
\text { follow up }\end{array}$ & $\begin{array}{l}\text { Recommended } \\
\text { placement }\end{array}$ & $\begin{array}{l}\text { Placement } \\
\text { at follow up }\end{array}$ & Findings at follow up \\
\hline \multicolumn{9}{|l|}{ Assessment } \\
\hline $1 / \mathrm{F}$ & I & 0-9 months & $\mathrm{BM}, \mathrm{BF}$ & 9 months & 4.5 years & SC & FP & $\mathrm{BM}$ has continuing psychiatric difficulties \\
\hline $2 / \mathrm{F}$ & Fs & 12 months & $\mathrm{BM}$ & 15 months & 2 years & $\mathrm{BM}$ & $\mathrm{BM}$ & Mild speech delay \\
\hline $3 / \mathrm{F}$ & Fs & $0-4.5$ years & $\mathrm{BM}, \mathrm{BF}$ & 4.5 years & 5 years & $\mathrm{BM}, \mathrm{SFa}$ & $\mathrm{BM}, \mathrm{SFa}$ & Mild developmental delay \\
\hline $4 / \mathrm{M}$ & Fs & $0-3.5$ years & $\mathrm{BM}, \mathrm{BF}$ & 3.5 years & 4 years & $\mathrm{BM}, \mathrm{SFa}$ & $\mathrm{BM}, \mathrm{SFa}$ & $\mathrm{BM}$ of cases 3 and 4 somatising and high parental stress \\
\hline \multicolumn{9}{|c|}{ Assessment and treatment } \\
\hline $5 / \mathrm{F}$ & I & 9 months (sib) & $\mathrm{BM}$ & 6 months & 2.5 years & $\mathrm{BM}, \mathrm{BF}$ & $\mathrm{BF}$ & Mild developmental delay \\
\hline $6 / F$ & I & $0-9$ months & $\mathrm{BM}$ & 9 months & 2.5 years & SC & $\mathrm{AP}$ & \\
\hline $7 / \mathrm{F}$ & $\mathrm{T}$ & $0-13$ months & $\mathrm{BM}$ & 13 months & 4 years & $\mathrm{BM}, \mathrm{BF}$ & $\mathrm{BM}, \mathrm{BF}$ & \\
\hline $8 / \mathrm{F}$ & I & $0-6$ months & BM & 11 months & 4.5 years & SC & $\mathrm{AP}$ & \\
\hline $9 / \mathrm{F}$ & I & $0-6$ months & $\mathrm{BM}$ & 6 months & 5.5 years & $\mathrm{BM}$ & $\mathrm{BM}$ & \\
\hline $10 / \mathrm{F}$ & Fs & $3-6$ years & $\mathrm{BM}, \mathrm{BF}$ & 6.5 years & 11 years & $\mathrm{BM}, \mathrm{BF}$ & $\mathrm{BM}, \mathrm{BF}$ & $\mathrm{BM}$ has alcohol problems \\
\hline $11 / \mathrm{M}$ & I & $0-3$ years & $\mathrm{BM}$ & 3 years & 7 years & $\mathrm{BM}, \mathrm{SFa}$ & $\mathrm{BM}, \mathrm{SFa}$ & BM depressed and anxious \\
\hline $12 / \mathrm{M}$ & I & $0-18$ months & $\mathrm{BM}$ & 2.5 years & 5 years & $\mathrm{BM}$ & $\mathrm{BM}, \mathrm{SFa}$ & $\begin{array}{l}\text { Mild developmental delay, behavioural problems } \\
\text { BM somatising and high parenting stress }\end{array}$ \\
\hline $13 / \mathrm{M}$ & I & 0-9 months & $\mathrm{BM}, \mathrm{SFa}$ & 9 months & 2.5 years & SC & $\mathrm{FP}$ & Mild developmental delay \\
\hline $14 / \mathrm{M}$ & I & $0-4$ years & $\mathrm{BM}, \mathrm{SFa}$ & 4 years & 7 years & $\mathrm{BM}, \mathrm{SFa}$ & $\mathrm{BM}, \mathrm{SFa}$ & BM somatising. High parenting stress \\
\hline $15 / \mathrm{M}$ & I & $0-1$ month & $\mathrm{BM}, \mathrm{BF}$ & 1 month & 18 months & $\mathrm{BM}, \mathrm{BF}$ & $\mathrm{BM}, \mathrm{BF}$ & Frequent general practitioner attender with child \\
\hline $16 / \mathrm{M}$ & I & $0-12$ months & $\mathrm{BM}, \mathrm{BF}$ & 18 months & 2.5 years & $\mathrm{BM}, \mathrm{BF}$ & $\mathrm{BM}, \mathrm{BF}$ & $\mathrm{BM}$ anxious and raised parenting stress \\
\hline $17 / \mathrm{M}$ & I & $0-3$ years & $\mathrm{BM}, \mathrm{BF}$ & 4 years & 4.5 years & $\mathrm{BM}, \mathrm{BF}$ & $\mathrm{BM}, \mathrm{BF}$ & \\
\hline
\end{tabular}

I, induced; Fs, falsification; T, tampering.

$\mathrm{BM}$, biological mother; $\mathrm{BF}$, biological father; $\mathrm{SFa}$, step father; $\mathrm{SC}$, substitute care; FP, foster parents; $\mathrm{AP}$, adoptive parents.

Fourteen of the 17 children (nine girls, eight boys) were aged 5 years or under at follow up, two were aged 7 , and one 11 . All except the 11 year old had been between the ages of 0 and 2 when abused (the 11 year old had been maltreated between 3 and 6 years). Table 1 includes the form of the original maltreatment that had led to child protection concerns. They were followed up from six months to four years and nine months (mean, 27 months). Length of stay in the family unit was from three days to four months (mean, seven and a half weeks).

\section{CARE RECOMMENDATIONS AT DISCHARGE AND} FOLLOW UP

The original placement recommendations made at discharge were followed in all cases. We recommended family reunification of 13 children with one or both natural parents, and alternative care for four. All living arrangements were still intact at the time of follow up, with the exception of one, who had changed from joint care by her birth mother and father at discharge, to sole care by her birth father at follow up. Her mother (the original abuser) abused her daughter six months after discharge from our unit by causing bleeding to the external auditory canal to simulate an appearance of an ear infection. A superficial scratch was discovered and an immediate decision taken to separate the child from her birth mother. Her father has subsequently continued to care for her adequately and with no instances of re-abuse over the subsequent two years' follow up. There were no other instances of re-abuse.

THE CHILDREN'S DEVELOPMENT

All children were within normal limits in terms of height, weight, and head circumference at the time of follow up. None were severely developmentally delayed but six children showed mild delays, four of which were among the treatment group. They comprised minor speech and language delays.

PARENTS' VIEW OF CHILD'S HEALTH

Most carers considered their child was healthy. This was confirmed by most of the general practitioners and the children themselves. Three children had confirmed physical problems, two of which were unrelated to previous maltreatment, and one had severe facial disfigurement as a direct consequence of the original induced illness, which required corrective craniofacial surgery. In five, the maternal perspective and that of the general practitioner were inconsistent. Four of these involved maternal exaggeration of symptoms, whereas in the other case the general practitioner was more worried than the child's mother about her daughter's eczema. In view of the original factitious illness by proxy abuse, the four instances of maternal exaggeration of symptoms are of particular interest.

The mother of case 12 perceived her child to be psychologically disturbed and possibly to suffer from problems such as anaemia and a speech defect, whereas her general practitioner considered the child to lie within normal limits. In cases 3 and 4 (siblings) the mother had attended or contacted her general practitioner with numerous complaints about minor physical ill health during the previous six months: 11 times regarding her children, six times about herself, and three times concerning her husband. There had also been additional unauthorised visits to specialists and to an aromatherapist. The mother of case 15 considered her child to have no health problems, yet had attended her general practitioner's surgery nine times in the previous six months, always with different complaints, and had called the emergency service on two occasions. In none of these four cases were symptoms fictitiously produced, but excessive health concerns appeared to persist, causing problems for the general practitioner and health visitor. However, all caused us concern for reasons other than the specific complaints for which their mothers were consulting their general practitioner. Our concerns were normally about the children's behaviour and/or relationship with their parents (see persisting concerns, below). 
BEHAVIOURAL AND EMOTIONAL PROBLEMS Parents or carers considered their children normal. Two cases scored above the cut off point on the behaviour check list. In the interviewer's view both these children showed evidence of mild disturbance during the assessment interview (cases 5 and 12), although they were not severe enough to warrant a referral for psychiatric assessment.

\section{MAIN CARER}

The families of nine children were receiving income support (social security benefit), and two received disability living allowance based on the child's "illness" (despite its factitious nature). Of the 12 birth mothers, nine were full time homemakers, and three worked part time.

\section{Carers' health}

Five carers (all biological mothers) showed evidence of some disturbance during the interviewer's brief mental state examination. Three showed signs of anxiety and mild depression and two were preoccupied with minor physical ailments, either in themselves or in their children. Two of the three mothers who showed signs of anxiety and depression also had raised general health questionnaire scores; all the other general health questionnaire scores were within the normal range.

Parenting capacity and social adjustment Five carers (or biological mothers) scored abnormally high on the parenting stress index, in particular with regard to their perception of their child, experience of depression in the care giving role, and poor support from family and friends.

The families' social adjustment was within the normal limits for the social adjustment scale, with the exception of one mother who was borderline, reflecting the frequent rows she was having with her neighbours (the mother of cases 3 and 4).

Carers' insight into factitious illness by proxy In all but one case where treatment had resulted in home placement there was retrospective insight by the main carer that she had originally harmed her child. This one mother appeared to have no insight into the original factitious illness by proxy abuse. We had concerns about her mental health and she frequently attended the general practitioner's surgery, yet her child was in good health and developing normally.

The situation was different for the four assessment cases. Among these one mother whom we recategorised as exaggerating symptoms, rather than factitiously producing them, did have limited insight, whereas the two mothers of the remaining three children had no insight into the concerns of the professionals, or the nature of their own behaviour.

PERSISTENT CONCERNS

The children's development and health were generally satisfactory, but concerns continued about frequent attendance at the general practitioner's surgery, maternal preoccupation with personal health, and, in some cases, the child's emotional state and relationship with his/her parents. Therefore, we developed our own researcher based assessment of families who displayed persisting concerns, to capture observations about levels of continuing risk and difficulty for the children, notwithstanding the absence of overt developmental difficulties or health problems. We made this composite rating in the following way:

(1) Serious concern (two families with a total of three children). These mothers tended towards excessive presentation for health concerns at their general practitioners's surgery, and/or had a disturbed relationship with their child. Although not overtly abusing, they sometimes showed little insight into their original condition and cooperated poorly with professionals.

(2) Mild concern (five families). These mothers had mild to moderate mental health problems, which did not impact significantly on their relationship with their child. Their children were developing normally. They usually displayed some insight into their condition and were working cooperatively and in partnership with professionals.

(3) No concerns (nine families). In these families the mothers did not have persisting mental health problems, had insight into their original condition, and were working appropriately and cooperatively with professionals. The children did not have psychological or physical disorders. The following case histories illustrate the two poles of this assessment.

\section{Serious concerns}

"D" was in his 1st year of life when abused by his mother. She diluted his feed so that he did not thrive and numerous investigations followed. Eventually " $D$ " was taken into foster care and when aged 2 years, admitted to the family unit together with his mother, with the prospect of family reunification. Relationships greatly improved and the family was reunited. $\mathrm{He}$ was the youngest child of a large sibship. Soon after discharge his mother remarried and at follow up, 21/2 years later, had borne two further children. His mother described " $D$ " as "hyperactive, aggressive, and psychologically disturbed". She perceived him as different from his siblings and described a poor attachment with him. She suspected that he might have a speech disorder and anaemia, for which she had contacted her health visitor and general practitioner. She had many health complaints herself, including fainting episodes, backache (for which she was attempting to claim compensation), and anaemia. Her insight into the previous admission was limited. "D" was overfamiliar with the researcher and appeared insecure and anxious in his attachment to his mother. His development was otherwise normal. The general practitioner found her frequent attendance unacceptable and was considering removing her from his list. The family did not receive continuing psychological help or social casework. 
No concerns

"C" was the only child of his single mother and described by her as having epilepsy. Although no other person had seen a fit, he was treated with anticonvulsants and at one point was admitted to hospital as a result of nonaccidental poisoning with prescribed anticonvulsant medication. His mother was found guilty in a criminal court of poisoning her child, and he was received into care. Six months later he and his mother were admitted to the family unit with a view to reunification. His mother fully acknowledged what had happened and his father similarly appreciated the harm that had occurred. Major improvements were seen in parent-child interactions, and the mother benefited from cognitive behaviour treatment for her propensity to somatise. At follow up "C" did not show any sequelae from the abuse itself, was well adjusted, development was within normal limits, and he appeared to enjoy a positive relationship with both parents. There was no evidence of continuing abuse or neglect.

\section{Discussion}

We have reported the outcome from a mixed group of cases from clinical practice that included all factitious illness by proxy cases admitted within a four year period to a specialised inpatient service. Cases ranged from fabrication to direct induction, as in other case series. ${ }^{12}$ Four cases were assessments only, whereas the other 13 were admitted with a view to treatment leading to family reunification. Ten of these 13 treatment cases were reunited with birth parents, whereas three left the unit with a recommendation for substitute care, where they have remained.

The crucial outcome is the children's welfare on follow up. We are encouraged at the overall picture, with most of the children doing well in terms of growth and development, particularly considering the severity of the original abuse. Nonetheless, we remain concerned about some of the children and their family situation. We will review the outcome from the assessment cases separately from the 13 treatment cases.

The four assessment cases were a mixed group. Three had been admitted to contribute to a paediatric evaluation of probable aetiology. Two of these were admitted for assessment of suspected factitious epilepsy, and one because of suspected induced failure to thrive. In two the diagnostic suspicion was confirmed with the help of ambulatory electroencephalography monitoring facilities. The inpatient assessment led to clarification of risk, and facilitated subsequent case planning by health and social services. Nonetheless, for the two factitious epilepsy cases it was several months (after the end of this research project) before definitive case plans could be made, and both children were separated from their abusive parent and placed with the non-abusive one. Thus, in these three cases the admission achieved the aim of diagnostic clarification. In the remaining assessment case, the admission to the unit clarified the diagnosis, confirmed the positive quality of the parent-child relationship, and resulted in a successful community based intervention.

The 13 treatment cases have reasonably good outcomes so far as the children are concerned, although some continued to live in suboptimal environments, where their mothers had persistent mental health difficulties and where there was disharmony or lack of secure attachment between the child and parent (one case about whom we had serious concerns and three about whom we had mild concerns). There was one child who suffered re-abuse, fortunately relatively mild from a physical perspective. The professional reaction was swift because the health and social services network had already been alerted to the possibility that re-abuse could occur in any form, not necessarily the same type as the index, original maltreatment. The child was separated from the abusive parent and her non-abusive father took on primary care, with the mother leaving the household. For the past two years these arrangements have continued uninterrupted and all contact with the child's mother has been supervised.

Although we do not have an untreated comparison group, a substantially higher rate of poor health and psychosocial outcomes, including re-abuse, would have been expected if these cases had received no intervention. For example, Davis et al reported a re-abuse rate of $20 \%$, which was significantly higher than this when all the children in the family were considered. ${ }^{9}$ Bools et al found further fabrications in one third of the children who remained with the original abuser in their follow up study, with serious further concerns about development or behaviour in a third of the sample.?

None of the siblings of index cases had been abused or maltreated. Two families have had further children since the original factitious illness by proxy, who are well. This contrasts with what is known of untreated cases $^{79}$ and, although the number is small, lends further weight to our conclusion that psychiatric intervention has been successful in altering the nature of the process of fabrication.

We found no evidence of continuing factitious illness by proxy in 12 of the 13 treated cases. However, although the mothers were not involving their children in continued factitious illness, two were presenting themselves unnecessarily to their general practitioners with exaggerated complaints of disease. One mother from the treatment group frequently attended surgery on behalf of her child, but was not fictitiously producing symptoms, rather tending towards over anxiety and some exaggeration of her child's symptoms. We cautiously conclude that psychiatric treatment has had the desired effect on the factitious illness by proxy process, but for a minority of parents the effect has been to shift their tendency to somatise along the continuum proposed by Eminson and Postlethwaite, ${ }^{24}$ from factitious production of symptoms towards more normal health seeking behaviour, while not fully achieving that goal. This observation has implications for long term 
monitoring of cases and further intervention for those mothers who are continuing to show abnormal illness behaviour. Interestingly, these same parents experienced looking after their children as a stressful and somewhat unrewarding task. The parenting stress index ${ }^{21}$ was useful in identifying these parents and is relatively simple to administer for the purposes of long term follow up.

There was also a small number of parents among the treated group who had continuing, yet mild, psychological difficulties. These consisted mostly of anxiety and depression. Some of these same mothers tended to have social difficulties, including rows with neighbours, continuing interpersonal problems, and arguments with the professionals who were attempting to care for them. An interesting question is whether the cases where persistent concerns were found had deteriorated after discharge from the family unit, or whether the scale and scope of their problems had not been fully identified during their inpatient admission. We are not able to answer this question satisfactorily, although the outcome of the present investigation has affected current clinical practice. Our unit is now more likely to seek parallel input from adult mental health providers concerning assessment of personality difficulties and the prospects for continuing treatment after discharge.

Non-abusive partners (or fathers and step fathers) appear to be very important to the outcome, although we did not have direct interview based information about them. In any future study it would be important to conduct family based interviews and make efforts to interview the non-abusive partner. We would also include a measure of family functioning in any further outcome research in this area.

A good outcome in this selected, small series of cases was associated with the following factors: acknowledgement of the factitious illness by proxy itself and the context of personal mental health difficulties, parenting problems, and other psychosocial problems in which it occurred; considerable improvement in personality style or other mental health problems; family system change, usually in the direction of increased openness of factual and emotional communications; increased parental awareness and sensitivity to their children's needs; and a realistic acceptance by the abuser of a continuing personal vulnerability and taking steps to prevent recurrence. The severity of the original abuse did not appear to be linked to the outcome when the above factors were present. However, this was a small series and we intend to assess these initial impressions in the light of more cases.

Since our study was completed we have become more selective in the cases admitted to the treatment programme, so that unnecessary disruption to the child is kept to a minimum. We have involved adult psychiatry in many of the assessments to improve the accuracy of assessments of personality and likelihood of response to psychological treatments. We advocate long term follow up particularly concerning maternal mental health, potential to return to somatising with respect to their own health, and attention to any deterioration in parent-child relationships. In addition, we concentrate to a greater extent than we used to on the family's continuing openness about what maltreatment occurred in their family. We work with the child's parents so that an honest account of the maltreatment and its circumstances is held by all key family members and friends over subsequent years (see Jones et al for a full description of this work $\left.^{15}\right)$.

These cases were highly selected so our results cannot be extrapolated to all cases of factitious illness by proxy. We speculate that it is only a small number of those cases at the severe end of the factitious illness by proxy spectrum where reunification can safely be achieved. However, family reunification was achieved safely in most of those who were selected for intervention, despite persisting problems for a minority of cases. Liaison and continuing back up support from the primary health care team, concerning child, maternal, and family mental health issues, is important to identify cases that might need further, community based intervention. We believe two of our treatment cases would benefit from further outpatient psychiatric treatment for the parent and parent-child relationship. We are keen to extend the follow up of these cases to determine whether our suspicions of incipient emotional problems for a minority are borne out. In addition, the treatment programme itself has developed and it would be important to determine the outcome for more recent cases. Meanwhile, for cases of factitious illness by proxy selected on the basis of parental acknowledgement of their difficulties and a likelihood for positive response to psychological treatments, psychiatric intervention may lead to successful family reunification and be in the child's best interests.

The authors would like to thank H Marcovitch for useful editorial advice, the anonymous referees for their helpful critical comments, and Dr C Bools for his advice in the writing of this paper.

1 Meadow R. Munchausen syndrome by proxy: the hinterland of child abuse. Lancet 1977 ;ii:343-4.

2 Jones DPH, Bools CN. Facititious illness by proxy. In: David $\mathrm{T}$, ed. Recent advances in paediatrics. Edinburgh: Churchill Livingstone, 1999:57-71

3 Meadow SR. Management of Munchausen syndrome by proxy. Arch Dis Child 1985;60:385-93.

4 Kempe RS, Kempe CH. The untreatable family. In: Kempe RS, Kempe CH, eds. Child abuse. London: Open Books, 1978:128-31.

5 Rosenberg D. Web of deceit: a literature review of Rosenberg D. Web of deceit: a literature review of
Munchausen syndrome by proxy. Child Abuse Negl

6 Samuels MP, McLaughlin W, Jacobson RR, Poets CF, Samuels MP, McLaughlin W, Jacobson RR, Poets CT,
Southall DP. Fourteen cases of upper airway obstruction. Arch Dis Child 1992;67:162-70.

7 Bools CN, Neale BA, Meadow SR. Follow-up of victims of fabricated illness (MSBP). Arch Dis Child 1993;69:625-30.

8 Neale B, Bools C, Meadow R. Problems in the assessment and management of Munchausen syndrome by proxy abuse. Children and Society 1991;5:324-33.

9 Davis P, McClure RJ, Rolfe K, et al. Procedures, placement and risks of further abuse following Munchausen syndrome by proxy, non-accidental poisoning, and non-accidental suffocation. Arch Dis Child 1998;78:217-21.

10 Southall DP, Plunkett MC, Banks MW, et al. Covert video recordings of life-threatening child abuse: lessons for child protection. Pediatrics 1997;100:735-60.

11 Lyons-Ruth K, Kaufman M, Masters $\mathrm{N}$, et al. Issues in identification and long term management of Munchausen by proxy syndrome within a clinical infant service. Infant Mental Health fournal 1991;12:309-30. 
12 Gray J, Bentovim A. Illness induction syndrome; paper 1-a series of 41 children from 37 families identified at great Ormond Street Hospital for Children. Child Abuse Negl 1996;20:655-73.

13 Gray J, Bentovim A, Milla P. The treatment of children and their families where induced illness has been identified. In Horwath J, Lawson B, eds. Trust betrayed; Munchausen syndrome by proxy, interagency child protection and partnership with families. London: National Children's Bureau, 1995: 149-62.

14 Jones DPH, Byrne G, Newbold C. Assessment of abusing families. In: Adshead G, Brooke E, eds. Munchausen's syndrome by proxy - a review. London: Imperial College Press. [In press.]

15 Jones DPH, Newbold C, Byrne G. Management, treatment and outcomes. In: Eminson M, Posslethwaite R, eds. Munchausen's syndrome by proxy: a practical approach. London: Butterworth Heinemann. [In press.]

16 Meadow R. What is, and what is not, "Munchausen syndrome by proxy?" Arch Dis Child 1995;72:534-8.
17 Bellman M, Cash J. Handbook for the schedule of growing skills. Windsor: NFER Nelson Publishing Company, 1996.

8 Walker L. The child somatization inventory. Nashville, USA: South Vanderbilt University Tennessee, Division of Adolescent Medicine, 1991.

19 Garber J, Walker L. 1991 Somatization symptoms in a community sample of children and adolescents: further validation of the children's somatization inventory. $\mathcal{F}$ Consult Clin Psychol 1991;3:588-95.

20 Richman M, Stevenson J, Graham P. Pre-school to school: a behavioural study. London: Academic Press, 1982.

21 Abidin R. Parenting stress index. Charlottesville, USA: Pediatric Psychology Press, 1990.

22 Goldberg D, Williams P. A user's guide to the general health questionnaire. Windsor: NFER Nelson Publishing Company, 1991

23 Weissman M, Bothwell S. Assessment of social adjustment by patient report. Arch Gen Psychiatry 1976;33:1111-15.

24 Eminson D, Postlethwaite R. Factitious illness: recognition and management. Arch Dis Child 1992;67:1510-26.

Febrile convulsions, rat brains, and scientific pessimism

Febrile convulsions are, by and large, benign. There is now a good deal of evidence to show that for the vast majority of affected children the prognosis is excellent. Why then does a commentary in Nature Medicine (1999;5:871-2) have the title "Febrile convulsions: a 'benign' condition?" It must be, surely, that some scientific advance has now shown that these children are at a considerable, previously unforeseen, risk. Not so. Not so at all.

What produced this commentary is an article from California (Kang Chen and colleagues. Ibid: 888-94) describing experiments on hyperthermia in young rats. These rats, when exposed at the age of 10 days to hot air, almost all developed mainly tonic seizures when their core temperature reached $40-41.5^{\circ} \mathrm{C}$. After such seizures, which lasted for about 23 minutes, the rats were decapitated and electrophysiological studies were performed on brain slices. They showed that after hyperthermic seizures there was a presynaptic increase in inhibitory transmission in the hippocampus. The inhibition was reversed by a GABA inhibitor and did not occur in rats subjected to hyperthermia but given pentobarbital to prevent seizures. Subsequent experiments suggested that the changes were brought about by increased activity of cyclic AMP dependent protein kinase. The inhibitory changes lasted into the animals' maturity (10 weeks after the induced seizures).

Increased inhibition, of course, might be a good thing and explain why children who have had febrile convulsions are not particularly prone to epilepsy. Chen and colleagues, however, point to evidence that increased inhibitory activity may lead to neuronal synchronisation, which could have a parodoxical convulsant effect. There are, however, differences between clinical febrile convulsions and these experimental convulsions. For instance, febrile convulsions in children are rarely caused by externally induced hyperthermia; perhaps the experiments should be repeated with pyrogen induced fever. But the proof of the pudding ... Which brings us back to my first two sentences.

Chen and colleagues conclude that their data "do not support the prevalent view of the 'benign' nature of early life febrile convulsions". I confess to being flummoxed by that conclusion, unless they have redefined the word benign. (Benign adj (from Latin, bene well and gignere to produce): a word used by neuroscientists to mean not producing any detectable change in the rat brain.) Could it be that the writers of scientific papers are more motivated to pessimism than to optimism? Perhaps pessimism pays.

ARCHIVIST 